\title{
Potencial imunomodulador de extrato etanólico de Momordica charantia L. em leite de vacas mastíticas
}

\author{
Immunomodulatory potential of ethanolic extract from Momordica charantia L. in mastic cow's \\ milk
}

Potencial inmunomodulatorio del extracto etanólico de Momordica charantia L. en mastic leche de

\section{Resumo}

A bovinocultura de leite é um importante setor da economia brasileira. Infelizmente, diversos fatores afetam a qualidade e a quantidade de leite produzido em unidades leiteiras, dentre eles a mastite. A mastite é uma doença caracterizada por inflamações nas glândulas mamárias, tendo diversas causas. O controle da mastite é feito a partir de manejo preventivo e uso de antibiótico intramamário. O uso frequente de antibióticos pode causar resistência, dificultando tratamentos posteriores. Portanto, estudos de fitoterápicos no controle da mastite vem se tornando mais frequente e com resultados promissores. Diversas plantas e extratos naturais já foram testados no controle da mastite. A planta estudada em questão é chamada de Momordica charantia L., conhecida popularmente como melão de São Caetano. Tal planta já demostrou inúmeros efeitos medicinais para diferentes finalidades. O objetivo deste trabalho consiste em analisar o potencial imunomodulador de Momordica charantia sobre células de leite de vacas mastíticas. Foram coletadas 20 amostras de leite, sendo dez de vacas sadias e dez de vacas com mastite clínica. Posteriormente, foram realizadas analises quanto a viabilidade celular, liberação de ânion superóxido, dosagem da enzima superóxido dismutase, fagocitose e atividade microbicida. Nas amostras que continham extrato observou-se uma diminuição do ânion superóxido e da enzima superóxido dismutase provavelmente devido ao mecanismo de escape das bactérias, e um aumento na atividade microbicida e na fagocitose sugerindo que o extrato de Momordica charantia seja um potencial imunomodulador contra a mastite bovina.

Palavras-chave: Mastite; Melão de São Caetano; Staphylococcus aureus. 


\begin{abstract}
Milk cattle farming is one of the main pillars of the Brazilian economy. Unfortunately, several factors affect the quality and quantity of milk produced in a milk units, among them a mastitis. Mastitis is a disease characterized by inflammation in the mammary glands, having several causes. The control of mastitis is done from preventive handling and with the use of intramammary antibiotic. Frequent use of antibiotics can cause resistance, making subsequent treatments difficult. Therefore, the study of phytotherapics in the control of mastitis has become more frequent and with promising results. Several plants and natural extracts have already been tested in mastitis control. The studied plant in question is called Momordica charantia, popularly known as Melão de São Caetano. This plant has demonstrated numerous medicinal effects for different purposes. This work aims to analyze the immunomodulatory potential of Momordica charantia on milk cells of mastitic cows. Twenty samples of cow's milk were collected, ten of which were healthy cows and ten cows with clinical mastitis. Subsequently, cell viability analysis, superoxide anion release, superoxide dismutase enzyme dosage, phagocytosis and microbicidal activity were performed. In samples containing extract a decrease in superoxide anion and superoxide dismutase enzyme was probably due to the escape mechanism of bacteria, and an increase in microbicidal activity and phagocytosis suggesting that the extract of Momordica charantia is an immunomodulatory potential against mastitis bovine.
\end{abstract}

Keywords: Mastitis; St Caetano melon; Staphylococcus aureus.

\title{
Resumen
}

La ganadería lechera es uno de los principales pilares de la economía brasileña. Desafortunadamente, varios factores afectan la calidad y cantidad de leche producida en las lecherías, incluida la mastitis. La mastitis es una enfermedad caracterizada por la inflamación de las glándulas mamarias, que tiene varias causas. El control de la mastitis se basa en el manejo preventivo y el uso de antibióticos intramamarios. El uso frecuente de antibióticos puede causar resistencia, lo que dificulta el tratamiento posterior. Por lo tanto, los estudios de medicamentos a base de hierbas para el control de la mastitis son cada vez más frecuentes y con resultados prometedores. Ya se han probado varias plantas y extractos naturales para controlar la mastitis. La planta estudiada en cuestión se llama Momordica charantia, conocida popularmente como Melão de São Caetano. Tal planta ya ha mostrado numerosos efectos medicinales para diferentes propósitos. El objetivo de este trabajo es analizar el potencial inmunomodulador de Momordica charantia en células de la leche de vacas con mastitis. Se recolectaron veinte muestras de leche, diez de vacas sanas y diez de vacas con mastitis clínica. Posteriormente, se realizaron análisis de viabilidad celular, liberación de anión superóxido, dosificación de la enzima superóxido dismutasa, fagocitosis y actividad microbicida. Las muestras que contienen extracto mostraron una disminución en el anión superóxido y la enzima superóxido dismutasa, probablemente debido al mecanismo de escape de las bacterias, y un aumento en la actividad microbicida y fagocitosis, lo que sugiere que el extracto de Momordica charantia es un potencial inmunomodulador contra la mastitis bovina.

Palabras clave: Mastitis; Melón São Caetano; Staphylococcus aureus.

\section{Introdução}

Atualmente o agronegócio do leite ocupa uma posição de destaque na economia do país e com grande expectativa para continuar crescendo nos próximos anos e com índices maiores que os alcançados em anos posteriores (Silva et al., 2017). De acordo com a Pesquisa Trimestral do Leite (IBGE, 2020), a aquisição de leite cru feita pelos estabelecimentos que atuam sob algum tipo de inspeção sanitária (federal, estadual ou municipal), no $4^{\circ}$ trimestre de 2020 , foi de 6,71 bilhões de litros. $\mathrm{O}$ valor correspondeu a um aumento de $0,6 \%$ em comparação ao volume registrado no 4o trimestre de 2019 e incremento de $4,1 \%$ em comparação ao obtido no trimestre imediatamente anterior.

Embora relevante, a produção de leite brasileira ainda sofre perdas econômicas significativas por diversos fatores, entre esses, os casos de mastite clínica, em que há sintomas inflamatórios na glândula mamária e subclínica, em que não há inflamação da glândula mamária, que quando passa desapercebida reflete em queda de produtividade. Estes quadros de mastite geram prejuízos tanto na quantidade quanto na qualidade do leite, e consequentemente na produção dos derivados lácteos. A mastite pode ser classificada em contagiosa: quando microrganismos contagiosos têm perfil de transmissão entre vacas, pois a glândula mamária é o principal reservatório desse patógeno, e ambiental: quando a transmissão ocorre a partir do ambiente da vaca (principal reservatório de patógenos ambientais) para a glândula mamária.

As prováveis fontes de infecção são os patógenos existentes nas mãos dos ordenadores, nas teteiras das ordenhadeiras e os patógenos existentes no ambiente (Costa, 2010). 
O controle da mastite se baseia em três princípios: manejo preventivo, ou seja, evitar que o animal entre em contato com o patógeno, aumento da resistência imunológica e uso de antibióticos (Brasil, 2012). Nos últimos anos o interesse no uso de produtos de origem natural se tornou mais constante, sensibilizando cientistas a ter maior dedicação no desenvolvimento de novas drogas com mais eficiência e menos toxidade. Nesse sentido os estudos de tratamentos mais naturais para o controle da mastite também foram estimulados, com o intuito de reduzir resíduos de antibióticos no leite destinado ao consumo humano (Pinto, 2000). Moghadam et al. (2016) afirmam que a ocorrência de resíduos de antimicrobianos no leite é consequência da utilização indiscriminada de fármacos, do desconhecimento técnico e descumprimento do período de carência das substâncias administradas, da ausência de cuidados na higienização de equipamentos e utensílios ou até mesmo por meio da adulteração, visando prolongar a vida útil da matéria-prima.

Atualmente muitos estudos têm evidenciado a atividade antibacteriana in vitro de extratos de plantas sobre patógenos infecciosos. Neste contexto, Costa (2010), em seu estudo demonstrou o efeito bactericida do extrato das flores de calêndula sobre Staphylococcus aureus de amostras de leite de vacas com mastite subclínica. Entre as plantas com ação bactericida, a Momordica charantia L. (melão de São Caetano) foi eficaz, inibindo algumas linhagens de patógenos estudadas, entre elas a Staphylococcus aureus, sugerindo a utilização dessa substância como meio alternativo de baixo custo no tratamento de afecções bucais, e, assim, justificando seu desenvolvimento tecnológico farmacêutico (Ponzi et al., 2010). Segundo Grover (2004) a Momordica charantia está distribuída em diversas regiões tropicais da Ásia, América do Sul, América Central e leste da África. A Momordica charantia L. é uma planta tropical da família das cucurbitáceas, de crescimento rápido, comum em terrenos abandonados, e sua ação antimicrobiana sobre o Staphylococcus aureus, o coloca como potencial imunomodulador para redução nos casos de mastite.

Diante do exposto, o objetivo deste estudo foi avaliar o potencial efeito imunomodulador de extrato hidro etanólico de Momordica charantia L. no controle de mastite bovina.

\section{Conjuntura Agropecuária do Leite no Brasil}

Tradicionalmente o Brasil é um grande produtor de leite, ocupando atualmente a quinta posição no ranking de maiores produtores mundiais de leite e sendo o maior produtor da América do Sul colocando esse produto em um lugar de destaque na economia do país (Seab, 2014).

De acordo com o Instituto Brasileiro de Geografia e Estatística (IBGE, 2018), de um total de 5.570 municípios 99\% produziram alguma quantidade de leite. Ao todo, foram produzidos 33,6 bilhões de litros de leite, sendo que mais de 70\% da produção está concentrada nas regiões Sul (37\%) e Sudeste (34\%). O restante é composto pelo Centro-Oeste (12\%), Nordeste (11\%) e Norte (6\%).

No ano de 2018 a produtividade aumentou em 4,7\% comparada ao ano anterior, chegando a $2.068 \mathrm{~kg} / \mathrm{vaca} / \mathrm{ano}$ (Carvalho et al., 2020). Entretanto, a produtividade ainda é considerada baixa, quando comparados a países como Estados Unidos da América (EUA) (10.457 kg/vaca/ano) e Nova Zelândia (4.237 kg/vaca/ano) (EMBRAPA 2019).

O Brasil possui um grande potencial exportador de lácteos, devido a abundância dos principais fatores de produção (terra, capital, trabalho e tecnologia), e é responsável por 7\% produção de leite mundial, no entanto ainda é importador de lácteos (EMBRAPA 2019).

Segundo estudo realizado pela Empresa Brasileira de Pesquisa Agropecuária - EMBRAPA (2019) a produção de leite no país em sua grande maioria, é caracterizada por uma gestão do negócio pouco profissionalizada e com diversos reflexos no custo de produção. Sinais disso estão na baixa produtividade dos fatores de produção, como vacas, mão-de-obra e capital investido; estrutura fragmentada e baixa escala de produção. 
Atualmente a cadeia produtiva do leite vem se modificando no Brasil, nota-se que os consumidores estão se tornando mais exigentes em relação aos produtos que consomem, além do interesse de exportação requerer uma melhor tecnificação e investimento no setor leiteiro para melhorar a qualidade do leite (Oecd, 2015). Neste sentido, a fim de garantir produtos de melhor qualidade, desde 2007 entrou em vigor, em todas as regiões do Brasil, a Instrução Normativa ${ }^{\circ} 51$ (Brasil 2002), atualmente substituída pela IN 62/2011 que dentre outros pontos determina novas normas para produção, identidade, qualidade e transporte do leite a granel (Brasil 2011).

Dessa forma a sanidade do rebanho representa um dos pilares de sustentação da produção de leite de qualidade, pois uma grande produtividade só pode ser obtida se cada um dos animais que compõem o rebanho estiver em um apropriado estado sanitário (Costa, 2010). Mendes et al. (2021) instituíram um plano de ação em dez fazendas leiteiras da região Sul do Brasil, que produziam leite de baixa qualidade, e monitorar as mudanças na qualidade e no ganho econômico, durante um ano. Pontos críticos foram identificados e um plano de ação baseado em boas práticas agrícolas e controle da mastite foi instituído, melhorando a qualidade do leite e, com isso, reduziu o descarte do leite no meio ambiente e aumentou a rentabilidade das propriedades estudadas.

No entanto, apesar das medidas implantadas no Brasil, assim como toda grande cadeia de produção existem ainda diversos fatores que são capazes de gerar perdas, na bovinocultura de leite por exemplo, as principais perdas são decorrentes de uma doença chamada de mastite que representa cerca de 12 a 15\% de perdas na produção (Embrapa, 2010).

\subsection{A Mastite Bovina}

A mastite é considerada uma das doenças mais importantes da cadeia leiteira do ponto de vista econômico. Caracteriza-se como uma inflamação da glândula mamaria causada normalmente por bactérias que invadem o úbere e se multiplicam (Gonçalves, 2012) acarretando modificação da composição do leite in natura com aumento da contagem de células somáticas. $\mathrm{O}$ alto índice de células somáticas no leite decorre principalmente do aumento de neutrófilos e constitui-se como o principal parâmetro utilizado para avaliar a sanidade do tecido mamário infeccionado (Lazzari et al., 2014).

Quanto a forma de manifestação podemos classificá-la de duas formas, a mastite clínica, que são os casos em que existem sinais evidentes, como edema, dor e endurecimento da glândula mamária, aumento da temperatura, formação de grumos ou pus no leite. Em casos mais graves, o animal pode apresentar perda de apetite, febre, perda de um ou mais quartos mamários e óbito (Cunha et al., 2016). A outra forma de manifestação é a mastite subclínica, caracterizada por alterações na composição do leite, como o aumento na Contagem das Células Somáticas (CCS) e nos teores de Cloro e Sódio, além da diminuição dos teores da lactose e gordura do leite (Santos et al., 2015).

Apesar de não ser possível diagnosticá-la visualmente, a mastite subclínica caracteriza-se pelo aumento acentuado de células imunológicas e de descamação do epitélio, o que possibilita a detecção dessa afecção por métodos indiretos, como a contagem de células somáticas. Essa ferramenta é importante no diagnóstico da mastite subclínica, sendo aceita internacionalmente como medida padrão para monitorar a sanidade da glândula mamária (Santos et al., 2015). A mastite também pode ser dividida em mastite contagiosa, provocada normalmente por micro-organismos do gênero Streptococcus spp., Staphylococcus spp. e Mycoplasma spp., e mastite ambiental causada por bactérias coliformes que estão presentes no ambiente que as vacas vivem (Gonçalves, 2012). A infecção por Staphylococcus aureus está entre a mais relevante. A bactéria em questão possui uma alta patogenicidade, trazendo grandes preocupações na cadeia produtiva do leite, bem como para a saúde pública.

$\mathrm{Na}$ forma contagiosa da doença o momento de maior risco de transmissão é na hora da ordenha. As bactérias de uma vaca contaminada podem ser transmitidas para uma vaca sadia através das mãos do ordenhador ou de teteiras contaminadas. 
Como estes micro-organismos são frequentes nos rebanhos leiteiros, aumenta-se a probabilidade de contaminação do leite cru e consequentemente a elevada produção de enterotoxinas, tornando-se um risco em potencial à saúde (Teixeira et al., 2017).

Neste cenário, esta doença oferece diversos riscos à saúde pública, pois constitui uma enorme ameaça à saúde dos consumidores devido à veiculação de patógenos e suas toxinas, sendo seu tratamento é mais difícil devido à elevada resistência aos antibióticos (Teixeira et al, 2017). Esta resistência, principalmente do Staphylococcus aureus aos antibióticos ocorre devido a mutações de seus genes com os genes de outras bactérias e pela alta infectividade de S. aureus associada a fatores de virulência que permitem sua disseminação no hospedeiro como a produção de toxinas e enzimas (Souza, 2010; Marques et al., 2013). Além disto, outra característica da mastite contagiosa é a grande quantidade de casos subclínicos em relação aos casos clínicos. Já na mastite ambiental os micro-organismos são transmitidos diretamente do ambiente para as glândulas mamárias. As principais fontes de infecção são camas orgânicas contaminadas, currais e piquetes embarrados. Quando comparada a mastite contagiosa a ambiental caracteriza-se por apresentar maior proporção de mastite clínica em relação a subclínica. (Voges et al., 2015).

Segundo a Embrapa 2010, a mastite subclínica é responsável por cerca de 90 a 95\% de todos os casos de mastite no rebanho, sendo sua incidência 15 a 40 vezes maior que a forma clínica. A mastite subclínica é a responsável pelas maiores perdas do produtor embora sua existência quase não seja notada em relação aos casos clínicos. O impacto causado pela mastite vai além dos prejuízos econômicos para produtor. O leite levado para os laticínios sofre mudanças na composição (redução em cálcio, fósforo, proteína e gordura, e aumento em sódio e cloro) reduzindo sua qualidade. Além desses prejuízos o antibiótico usado no tratamento da mastite como vimos é uma preocupação importante para a indústria e para a saúde pública. O uso de antibiótico pode deixar resíduos no leite que interferem no processo de fabricação de alguns lácteos gerando sabores indesejáveis que reduzem o valor dos produtos. Mesmo a presença de antibióticos sendo de níveis baixos pode causar problemas de saúde nos consumidores (Tozzetti et al., 2008). Desta forma, a presença de isolados microbianos multirresistentes no leite bovino e em isolados clínicos mostra a importância da escolha e a utilização de agentes antimicrobianos adequados para o tratamento efetivo da mastite (Krewer et al., 2013).

\subsection{Uso de plantas medicinais no controle de enfermidades}

O uso de plantas medicinais advém do conhecimento empírico, o qual foi adquirido e acumulado durante milênios e que é transmitido através da cultura popular (Freitas et al., 2014). No entanto, apesar das plantas medicinais já fazerem parte da cultura popular a muito tempo, foi somente nas últimas décadas que o interesse pela Fitoterapia teve um aumento considerável entre usuários, pesquisadores e serviços de saúde. Segundo a Organização Mundial da Saúde (OMS) 80\% da população dos países em desenvolvimento utilizam práticas tradicionais nos seus cuidados básicos de saúde e $85 \%$ usam plantas medicinais ou preparações destas. Desde então, a OMS tem expressado a sua posição a respeito da necessidade de valorizar a utilização de plantas medicinais no âmbito sanitário e na atenção básica à saúde (Rosa et al., 2011). Devido ao elevado custo de medicamentos e da baixa condição financeira da maior parte da população global, as plantas constituem de importantes aliados na prevenção e combate a doenças (Freitas et al., 2014). A maior parte dos recursos biológicos utilizados para tratamento da saúde nos sistemas médicos tradicionais hoje é obtida a partir de vegetais, utilizados inteiros ou fragmentados (Neto et al., 2015).

As propriedades medicinais das plantas são devidas à presença de certas substâncias químicas que podem provocar uma ação fisiológica no corpo humano. As várias partes da planta, tais como raízes, folhas e frutos contêm compostos bioativos como componentes alcalóideos, óleos essenciais, péptidos e insaturados, aldeídos de cadeia longa, tornando-os ricos como fonte de remédio. Além disso, Doughari et al., (2008) indicaram que estes compostos bioativos são eficazes contra agentes patogênicos humanos como bactérias, fungos e vírus, o que pode ser excelente significativo em tratamentos 
terapêuticos. A importância das plantas medicinais tem sido revelada por estudos etnobotânicos realizados em diversas regiões brasileiras, abrangendo os biomas como: Mata Atlântica (Costa, 2011), Cerrado (Cunha, 2011), Caatinga (Marinho et al., 2011), Pantanal (Oliveira et al., 2011) e Amazônia (Coelho-Ferreira, 2009; Costa, 2010; Evangelista et al., 2013). No entanto, apesar dos vários estudos já realizados na área, em grande parte dessas regiões ainda possuem plantas medicinais indicadas popularmente, das quais ainda não foram realizados nenhum estudo químico, farmacológico ou toxicológico (Almeida, et al., 2011).

A Momordica charantia L. é uma planta de origem asiática que foi introduzida no Brasil a partir da África, caracteriza-se como uma planta anual, trepadeira, muito ramificada, com caules muitos ramificados que chegam a atingir de 2 a 3 metros de comprimento (Lorenzi, 2008). Além de ser uma espécie monoica onde a flor apresenta coloração amarelo claro e exalam um odor suave que tende a aumentar durante a manipulação. A flor masculina possui pétalas fundidas na base do receptáculo, cinco estames unidos pelas anteras. Já a flor feminina é epígina, com longo pecíolo além de não produzir néctar (Lenzi et al., 2005).

Figura 1 - Foto da planta de Momordica charantia à direita mostrando seu fruto e foto à esquerda mostrando suas flores monoicas.
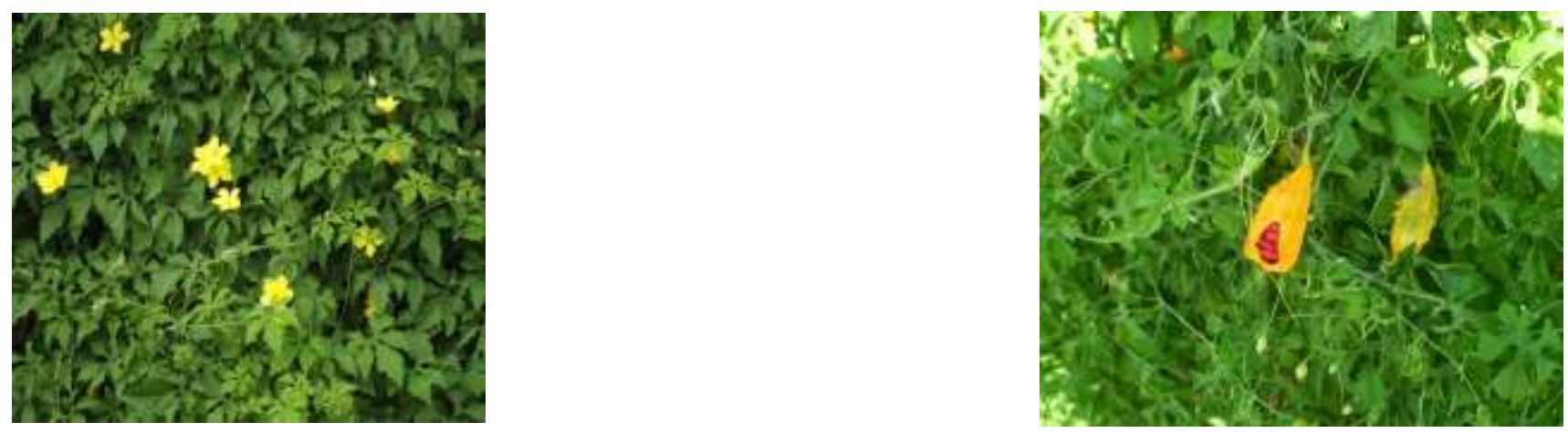

Fonte: Internet.

Sua espécie pertencente à família das cucurbitáceas, onde muitas espécies desta família são comestíveis e reúnem importante valor econômico alimentícia e farmacoterapêutica no Brasil (Lenzi et al., 2005) especialmente aquelas do gênero Cucurbita, Momordica, Fevillea e Sechium. Esta planta silvestre também conhecida como Melão de São Caetano é comumente encontrada em áreas urbanas e rurais, com grande ocorrência em todo o território brasileiro, pois se trata de uma planta muito rustica com grande capacidade de adaptação (Lorenzi, 2008) sendo conhecida e utilizada por suas propriedades medicinais sendo indicada para Inflamações hepáticas, diabetes, cólicas abdominais, problemas de pele, queimaduras com leucorréias purulentas, furúnculos e hemorroidas, triglicerídeos, prisão de ventre, tosse, cicatrização de feridas, infecções, Sarampo, hepatite; febres entre outras (Yeo et al., 2014; Assis et al., 2015).

Toda a planta de Momordica charantia, incluindo a frutas, sementes, folhas e caule possuem valores medicinais e exercem efeitos terapêuticos como antidiabéticos, antivirais, antioxidantes, atividades anticancerígenas e anti-HIV (Yeo et al., 2014). Vários estudos têm demostrado que esta planta tem papel no desenvolvimento de uma grande variedade de atividades farmacológicas, como antidiabéticos (Fuangchana et al., 2011), antioxidantes (Rakholiya et al., 2011) atividades anticancerígenas (Pitchakarn et al., 2012) e antiulcerativa (Grover, 2004). No entanto, embora numerosos estudos foram feitos em Momordica charantia L., a maioria dos estudos foram feitos para o tratamento do diabetes, enquanto apenas alguns estudos foram feitos na atividade antimicrobiana (Yeo et al., 2014). Além disto, estudos que relacionam Momordica charantia L. e mastite bovina são pouco existentes, reforçando a importância de se estudar a capacidade imunomoduladora desse extrato. 
$\mathrm{O}$ uso de extratos vegetais de conhecida atividade antimicrobiana pode adquirir significado nos tratamentos terapêuticos (Eller et al, 2015). Neste caso, o uso da Momordica charantia L. pela ação contra o Staphylococcus aureus pode tornar-se uma opção natural no controle da mastite. Estes testes são ainda mais importantes se considerarmos que as bactérias causadoras da mastite em bovinos vêm adquirindo cada vez mais resistência as antibioticoterapias (Lopes et. al., 2013). Na tentativa de amenizar essas preocupações, novos métodos têm sido adotados para controlar a mastite bovina causada por bactérias e entre estas alternativas está o uso de extratos extraídos de plantas, que trazem consigo uma complexidade de elementos e resultados satisfatórios em experimentos (Millezi et al., 2014).

\section{Metodologia}

A fase experimental da pesquisa foi realizada no Laboratório de Cronoimunomodulação e Imunologia da Relação Materno-Infantil pertencente a Universidade Federal de Mato Grosso, Campus Universitário do Araguaia, situado no município de Barra do Garças - MT, com o intuito de se analisar a capacidade imunomoduladora do extrato de Momordica charantia L.

\subsection{Obtenção das amostras de leite}

As amostras foram coletadas na Fazenda Cristo Rei situada no perímetro rural de Barra do Garças - MT (latitude $15^{\circ}$

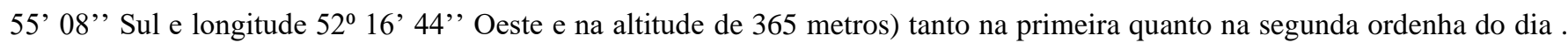
Foram coletadas amostras de leite de vacas sadias $(n=20)$ e de leite de vacas mastíticas $(n=20)$, tais amostras foram colocadas e tubos Falcon, transportadas e congeladas para posterior análise.

As amostram foram então separadas em 4 grupos sendo $1^{\circ}$ o grupo controle com leite normal coletado das vacas sadias sem a presença de extrato $(\mathrm{n}=10)$, o $2^{\circ}$ grupo com leite normal com adição do extrato da planta Momordica Charantia $(\mathrm{n}=10)$, o $3^{\circ}$ grupo foi composto por leite de vacas mastíticas sem a presença do extrato $(\mathrm{n}=10)$ e $4^{\circ}$ grupo com leite de vacas mastíticas e adição do extrato de Momordica Charantia $(\mathrm{n}=10)$.

\subsection{Preparação do extrato etanólico}

A Momordica charantia foi coletada no perímetro urbano de Barra do Garças - MT (latitude $15^{\circ} 55^{\prime}$ '08' Sul e longitude 52 $16^{\prime}$ '44" Oeste e na altitude de 365 metros), analisada e reconhecida pelo Laboratório de Morfologia Vegetal da Universidade Federal de Mato Grosso - Campus do Araguaia. A partir de então foi preparado o extrato etanólico através da maceração de todas as partes aéreas da planta. Com o auxílio de um almofariz macerou-se $200 \mathrm{~g}$ da planta que em seguida foi colocada em um frasco com 1 litro de álcool absoluto e mantida longe em ambiente escuro por 15 dias. Ao final dos 15 dias esse extrato foi filtrado, rota-evaporado, levado à estufa por mais três dias e depois ressuspendido em $10 \mathrm{ml}$ de água destilada.

\subsection{Separação de células do leite}

As amostras de leite foram retiradas do freezer para descongelar, após esse período foi realizada a separação das populações celulares por gradiente de densidade Ficoll-Paque (Pharmacia), durante $40 \mathrm{~min}$ a $160 \mathrm{G}$ em temperatura ambiente. $\mathrm{O}$ anel enriquecido de fagócitos mononucleares foi retirado e reservado. As células foram então lavadas duas vezes em solução salina tamponada (PBS). A seguir foi realizada a contagem em câmara de Neubauer, e as concentrações celulares foram ajustadas para $2 \times 10^{6}$ células $/ \mathrm{mL}$. 


\subsection{Dosagem de ânion superóxido}

Para a verificação da ativação celular foi analisada a liberação de ânion superóxido pelos fagócitos, sendo determinada pela utilização do cromógeno citocromo C (Sigma, St Louis, MO, USA), segundo o método Pick e Mizel (1981) adaptado por Honorio-França et al. (1997). Em presença do ânion superóxido o ferricitocromo C sofre oxidação passando a ferrocitocromo C. Essa mudança colorimétrica é detectável em espectrofotômetro com filtro de 550nm.

Após o período de incubação das soluções celulares, os tubos foram centrifugados a 160G e o sobrenadante foi desprezado. As células foram ressuspendidas em PBS glicosado contendo ferricitocromo C (concentração de $2 \mathrm{mg} / \mathrm{mL}$ ). Um controle contendo somente células foi realizado paralelamente para a verificação da liberação espontânea do ânion superóxido. As suspensões foram colocadas em placas de cultura celular de 96 poços, deixando-as em estufa a $37^{\circ}$ por uma hora. A leitura foi feita em espectrofotômetro para placas com filtro de 550nm (Thermo Plate TP-Reader). A concentração do ânion superóxido foi calculada segundo o método adaptado de Pick e Mizel (1981), no qual é estabelecida seguinte relação:

$\left[\mathrm{O}_{2}^{-}\right]=\mathrm{DO} \times 100 / 6,3$ expressos em nmol $/ \mathrm{ml}$

onde, $\left[\mathrm{O}_{2}^{-}\right]$trata-se da concentração de ânion superóxido e DO é a densidade óptica.

\subsection{Determinação da atividade enzimática da superóxido dismutase}

A determinação da atividade enzimática da $\mathrm{Cu}-\mathrm{Zn}$ superóxido dismutase (CuZn-SOD) foi realizada no sobrenadante dos fagócitos após incubação com estímulos por 30 minutos. A análise foi realizada a partir a partir da inibição da redução do azul de nitrotetrazolio (NBT) (Sigma, St Louis, MO, USA) pelo ânion superóxido e lidas com espectofotometro a $560 \mathrm{~nm}$ (CROUCH et al., 1981). A enzima catalisa o ânion superóxido que é gerado pela adição de hidroxilamina em ph alcalino.

Foi então adicionado $0,5 \mathrm{ml}$ de mistura clorofórmio-etanol (1:1), $0,5 \mathrm{ml}$ da mistura reativa de NBT e ácido etilenodiamino tetra-acético (EDTA) (1:1.5) e 2,0 ml de tampão carbonato com hidroxilamina, e incubados em temperatura ambiente por 15 minutos e após esse período a reação foi parada com gelo. A mistura reativa foi utilizada como branco para calibrar o aparelho e para a análise do padrão foram utilizados $0,5 \mathrm{ml}$ de uma mistura etanólica (1:4) para a reação no lugar da amostra. A quantidade de enzima foi determinada a partir da seguinte relação SOD= (Ab. Padrão - Ab. Amostra/ Ab. Padrão) $\times 100=\%$ de redução do NBT/Cu-Zn-SOD. O resultado foi expresso em unidades internacionais (UI) de CuZn-SOD.

\subsection{Avaliação da fagocitose, atividade microbicida e viabilidade celular}

A fagocitose foi avaliada pela técnica de Microscopia de Fluorescência laranjado de acridina (Bellinati-Pires et al.,1989). Após o período de incubação, as suspensões de células e bactérias foi submetida a centrifugação por 10 minutos à 160G. O pallet foi corado com $200 \mu \mathrm{l}$ de acridina Orange na concentração de $14,4 \mathrm{mg} / \mathrm{ml}$ por 1 minuto, a seguir foi ressuspendido em PBS. As soluções foram centrifugadas e lavadas com PBS mais duas vezes, a partir daí foram montadas lâminas e realizada a contagem em microscópio de fluorescência (Nikon Eclipse E 2000, Nikon Corporation, Tokyo, Japan). Os grupos controles descritos anteriormente foram utilizados para a realização de análise da viabilidade dos fagócitos perante o extrato e verificação da atividade fagocitaria em relação a Staphylococcus aureus na ausência de outros estímulos.

As análises de viabilidade e fagocitose são representadas em porcentagem a partir da contagem de 100 células. Para análise de viabilidade as células são classificadas como vivas (verde) e mortas (vermelha) perante a coloração diferencial. Para a análise de fagocitose as células são classificadas de acordo com a ocorrência de fagocitose e de morte intracelular de bactéria. 


\subsection{Análise estatística}

Os dados obtidos no experimento foram submetidos ao teste de Análise de Variância (ANOVA), em delineamento experimental inteiramente casualizado, seguido de comparações múltiplas pelo teste de Tukey, considerando diferença estatística quando $\mathrm{p}<0.05$.

\section{Resultados e Discussão}

A análise de viabilidade celular foi realizada pelo método de laranja de acridina, observa-se que não houve diferenças significativas entre amostras de leite normal ou mastítico, com ou sem extrato de Momordica charantia L., com valor médio de 94\% das células viáveis (Tabela 1). Desse modo, o extrato de Momordica charantia L. não alterou a viabilidade dos fagócitos, confirmando que esta planta não tem efeito toxico sobre as células, indicando segurança dessa planta medicinal como medicamento. Assim como o extrato de Momordica charantia o extrato de Lippia sidoides não interferiu na viabilidade dos fagócitos, demonstrando que a toxidade permaneceu nos parâmetros aceitáveis sobre as células (Gonzatti, 2015).

Tabela 1. Valores médios \pm desvio padrão do índice de Viabilidade Celular (\%) das amostras de leite.

\begin{tabular}{lc}
\hline Grupos & Viabilidade Celular (\%) \\
\hline Leite Normal & $94,2 \pm 3,59$ \\
Leite Normal+Extrato & $93,2 \pm 2,57$ \\
Leite Mastitico & $94,8 \pm 3,02$ \\
Leite Mastitico+Extrato & $94,4 \pm 2,60$ \\
\hline
\end{tabular}

Fonte: Autores.

As plantas medicinais são objetos de estudos na tentativa de descobrir novas fontes de princípios ativos. Estudos vêm demonstrando que a utilização de plantas pode estimular células e atuar como forma alternativa no tratamento de várias doenças (Honorio, 1995; Honorio-França et al., 2001; Corrêa et al., 2006). A estimulação celular pode ser observada pela ativação do metabolismo oxidativo com liberação de radicais livres. Os efeitos benéficos dos radicais livres no organismo humano, parecem ser a participação nos processos de fagocitose e atividade microbicida, que visam eliminar os agentes potencialmente patogênicos (França et al., 2011).

A eliminação de microrganismo após a fagocitose pode ser mediada por dois mecanismos: metabolismo oxidativo com produção de metabólitos ativos do oxigênio ou liberação de enzimas lisossômicas. É importante salientar que a geração do ânion superóxido tem papel central e, é a base para a formação dos outros radicais. Os métodos de avaliação indireta da atividade dos fagócitos podem ser realizados através da detecção de produtos do metabolismo oxidativo como o ânion superóxido (Corrêa et al., 2006).

De acordo com resultados obtidos, nota-se que houve uma diminuição das concentrações de ânion superóxido pelos fagócitos no grupo de vacas normais com adição do extrato da planta (N+E) e nos grupos de vacas mastite (M) e vacas mastite com adição do extrato da planta (M+E) quando comparado ao grupo de vacas normais sadias $(\mathrm{N})$, como podemos observar na Figura 2.

O estresse oxidativo ocorre quando a produção de espécies reativas de oxigênio (EROs) excede os mecanismos de defesa por meio dos antioxidantes do organismo animal (Spears; Weiss, 2008). Assim, o estresse oxidativo pode ocorrer no organismo a partir de um aumento na produção de EROS e uma resposta insuficiente ou ineficaz do sistema de defesa antioxidante, enzimático ou não, ocorrendo devido à carência de vitaminas e minerais, processos inflamatórios exacerbados, deficiências do sistema imune, situações de exercício intenso e condições exógenas (Baskin et al., 2000). Em baixos níveis, as 
ERO's podem ser vantajosas para as células, ativando caminhos de sinalização que promovem proliferação ou sobrevivência celular, por outro lado, em níveis mais elevados, podem danificar ou destruir células através da oxidação de proteínas, lipídios e ácidos nucleicos (Gill et al., 2016).

Possenti et al. (2018) observaram redução dos níveis dos marcadores oxidativos após o tratamento com o extrato de Mentha arvensis L., demonstram uma ação antioxidante frente aos eritrócitos de bovinos leiteiros, principalmente nas vacas saudáveis e nas vacas com mastite e sem tratamento prévio com antibióticos. A busca por terapias alternativas naturais tanto para a prevenção como para o tratamento da mastite bovina são fundamentais para diminuir o efeito dos radicais livres o que pode explicar os achados neste estudo.

Em um estudo realizado por Ormonde (2012) observou-se um aumento na produção de ânion superóxido nas células de sangue humano moduladas com o extrato de Momordica charantia, contradizendo os resultados encontrados em nossa pesquisa.

Figura 2. Dosagem de ânion superóxido $\left(\mathrm{O}_{2}\right)$ das células de leite na presença de extrato etanolico de Momordica charantia L.

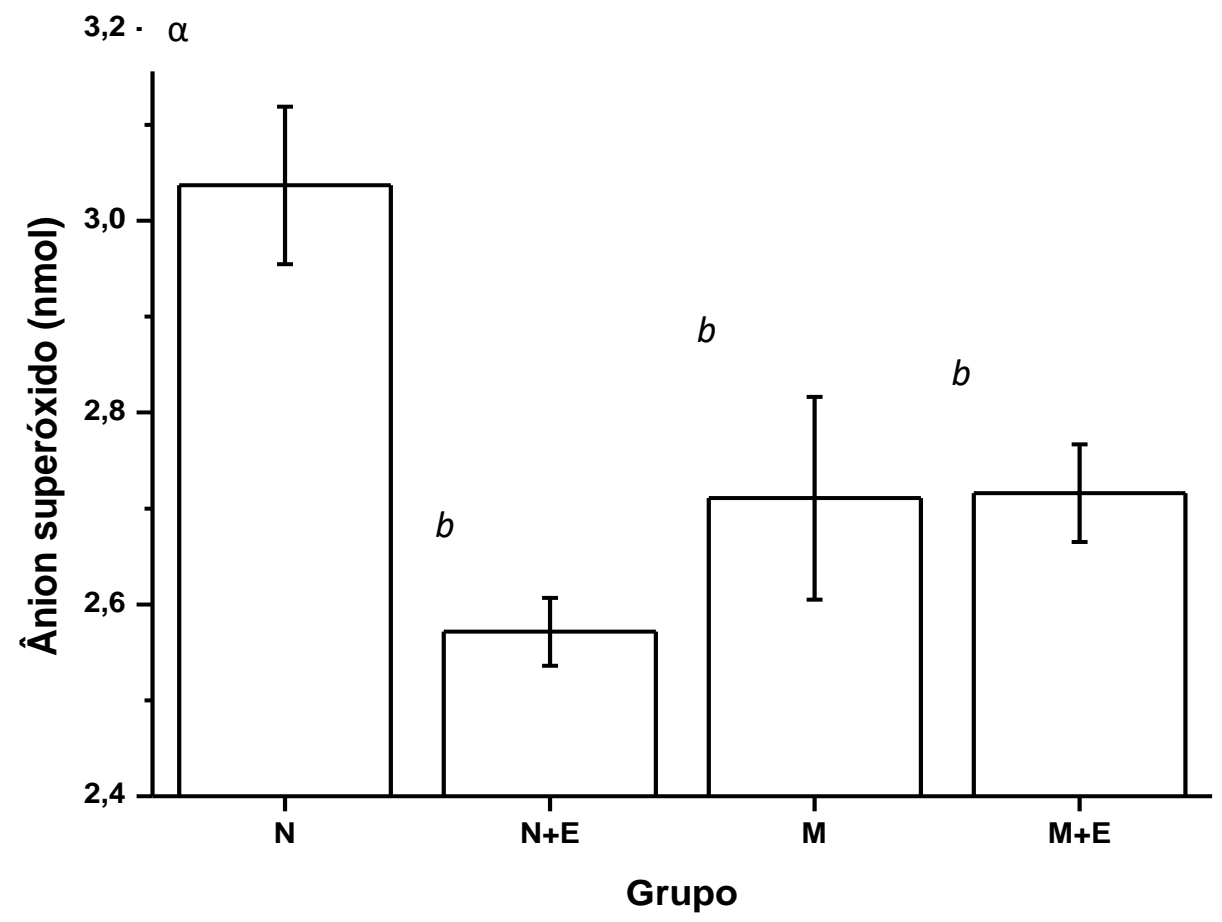

Legenda. $\mathrm{N}=$ Grupo de leite de vacas normais; $\mathrm{N}+\mathrm{E}=$ Grupo de leite de vacas normais com adição de extrato de Momordica charantia $;$ M = Grupo de leite de vacas Mastíticas; $\mathrm{M}+\mathrm{E}=$ Grupo de leite de vacas mastíticas com a adição de extrato de Momordica charantia.

A fagocitose é apontada como o melhor mecanismo de defesa contra a infecção bacteriana no úbere bovino, no entanto, apesar de ser a mais eficiente defesa natural contra infecção na glândula mamária por $S$. aureus mesmo em condições fisiológicas normais, a fagocitose muitas vezes é comprometida devido aos mecanismos de escape que estas bactérias vêm desenvolvendo se tornando resistentes a fagocitose (Bandeira, 2015). Os resultados desta pesquisa mostraram que o extrato de Momordica Charantia L. foi capaz de aumentar a fagocitose das células quando comparado aos grupos de vacas normais e vacas mastíticas, apesar de não apresentar diferenças significativas (Figura 3). 
Figura 3. Índice de Fagocitose (\%) das células de leite na presença do extrato de Momordica charantia L.

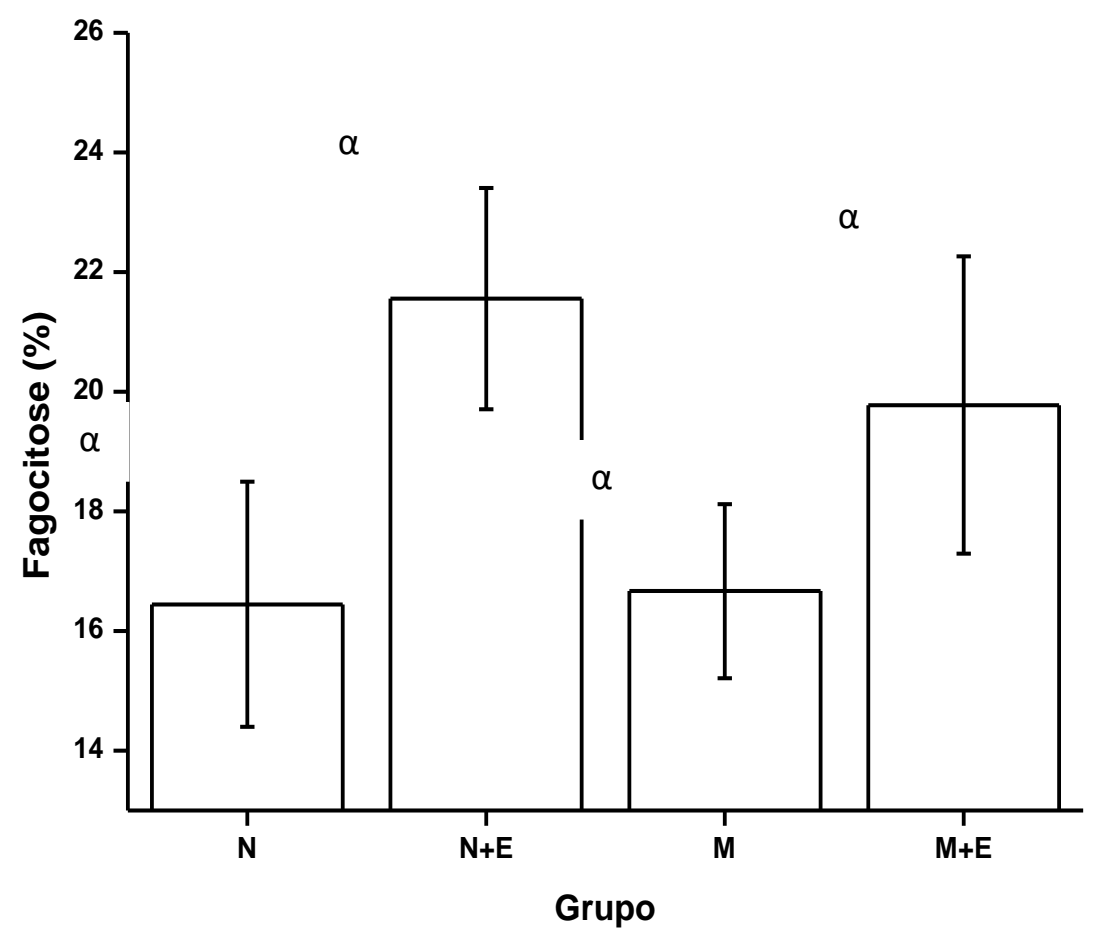

Legenda. $\mathrm{N}=$ Leite de vacas normais; $\mathrm{N}+\mathrm{E}=$ Leite de vacas normais com adição de extrato de Momordica charantia $; \mathrm{M}=$ Leite de vacas mastíticas; $\mathrm{M}+\mathrm{E}=$ Leite de vacas mastíticas com a adição de extrato de Momordica charantia $L$.

Figura 4. Diferentes imagens da fagocitose de células de leite em microscopia de fluorescência. Barra do Garças-MT/ 2017.

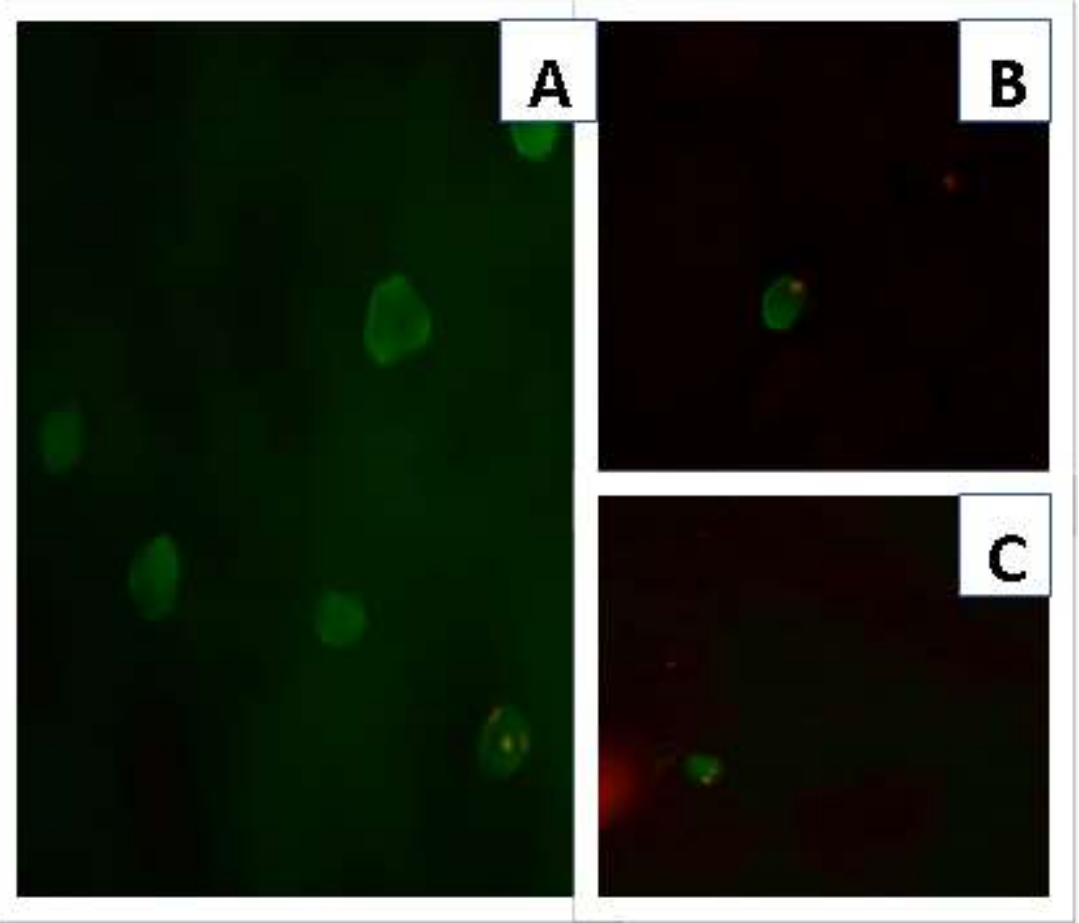

Letra A: Grupo de Leite de vacas normais com adição de extrato de Momordica charantia.

Letra B: Grupo de Leite de vacas mastíticas com a adição de extrato de Momordica charantia L. Letra C: Grupo de Leite de vacas normais.

Fonte: Arquivo pessoal. 
Em relação a atividade microbicida das células, observa-se que tanto as amostras oriundas de vacas mastíticas quanto o grupo contendo extrato foram capazes de aumentar a atividade microbicida destas células quando em contato com a bactéria (Figura 5). O extrato de Momordica Charantia L. demonstrou ser capaz de aumentar a atividade microbicida dos macrófagos mostrando-se efetivo para o controle da mastite. As amostras de leite de vacas com mastite também obtiveram um aumento desta atividade devido provavelmente ao fato de que estas vacas já serem sensibilizadas contra a bactéria. Segundo Pereira et. al (2010), o gênero Staphylococcus é o agente causador de mastites e outras doenças de difícil controle. No estudo realizado pelos autores o efeito do extrato de Momordica Charantia L. sobre linhagens de Staphylococcus aureus de origem bovina foi observado que o extrato desta planta apresentou atividade antimicrobiana, corroborando com nossos resultados.

A relevância do estudo da Momordica Charantia L. como imunomodulador para tratamento ou controle de mastite bovina está na possibildade de aumentar as opções de extratos naturais com esta finalidade. Costa (2010) ao avaliar o extrato etanólico das flores de Calendula officinalis verificou atividade antibacteriana sobre Staphylococcus aureus nas concentrações de 50 a $0,39 \mathrm{mg} \mathrm{mL}^{-1}$ do extrato bruto, verificou-se que as menores concentrações dos extratos que inibiram o crescimento do microrganismo.

Figura 5. Índice de atividade microbicida (\%) das células de leite na presença do extrato de Momordica charantia.

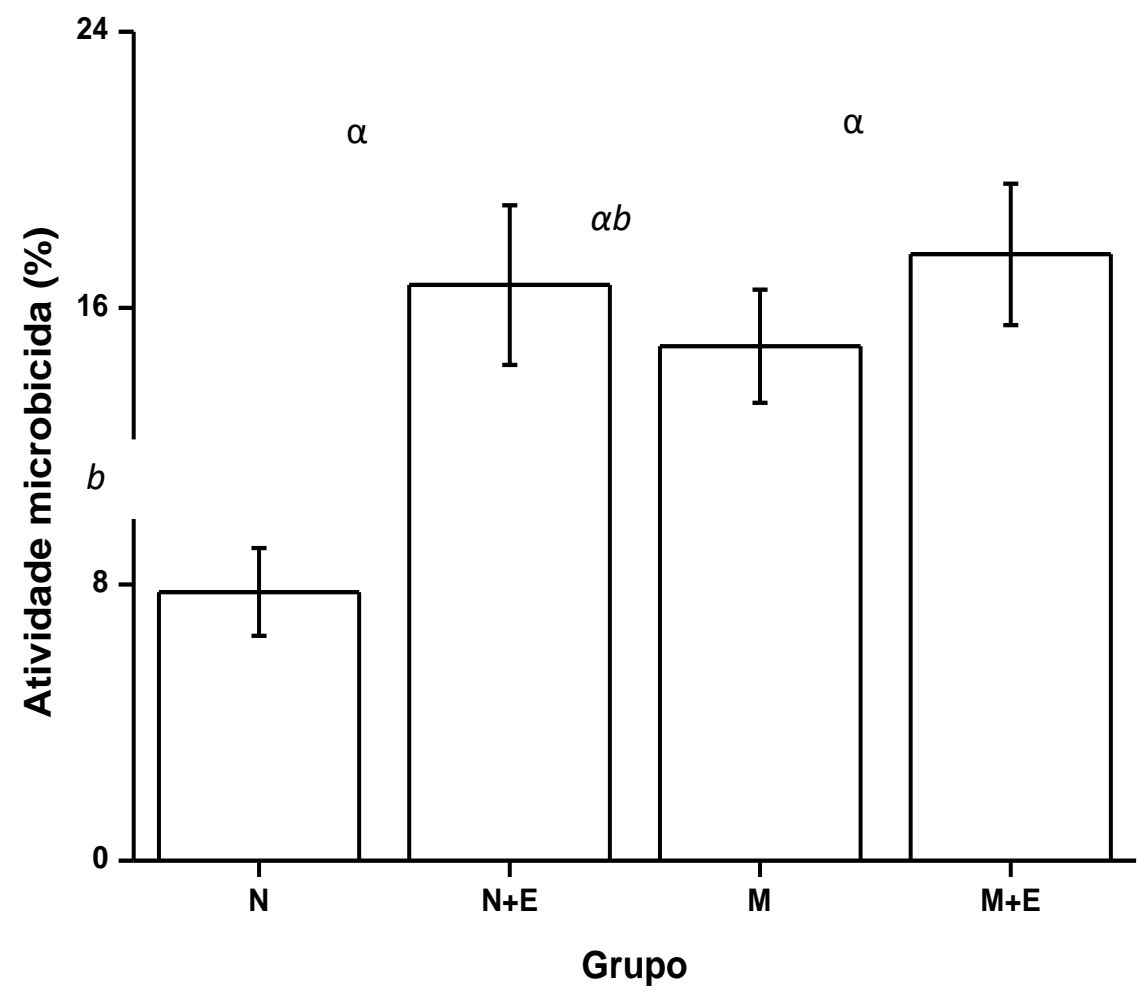

Legenda. $\mathrm{N}=$ Leite de vacas normais; $\mathrm{N}+\mathrm{E}=$ Leite de vacas normais com adição de extrato de Momordica charantia $; \mathrm{M}=$ Leite de vacas Mastíticas; $\mathrm{M}+\mathrm{E}=$ Leite de vacas mastíticas com a adição de extrato de Momordica charantia.

Dentre os antioxidantes enzimáticos mais analisados, destacam-se as superóxidos dismutases, consideradas como a primeira forma de defesa antioxidante. (Oliveira, et. al, 2009). No que se refere a sua atividade enzimática observa-se uma diminuição na concentração desta enzima nos grupos que tiveram adição do extrato da planta (Figura 6). Enzimas antioxidantes como a superóxido dismutase fazem parte de um mecanismo de defesa que ajuda a proteger as bactérias entéricas 
da toxicidade do oxigênio (Das, 2008). Desta forma o SOD pode ser usada como mecanismo de escape para as bactérias do gênero Staphylococcus, por exemplo, por diminuir a concentração de ânion superóxido liberado pelos fagócitos, permitindo assim a sobrevivência dentro das células. Em nosso estudo, houve uma diminuição na concentração de SOD nos grupos de vacas normais e vacas mastites com adição do extrato, mostrando que o extrato de Momordica Charantia L. além de aumentar a atividade microbicida dos fagócitos ainda sugere uma diminuição dos mecanismos de evasão das bactérias por meio da diminuição das concentrações de SOD.

Figura 6. Dosagem da enzima superóxido dismutase (CuZn-SOD).

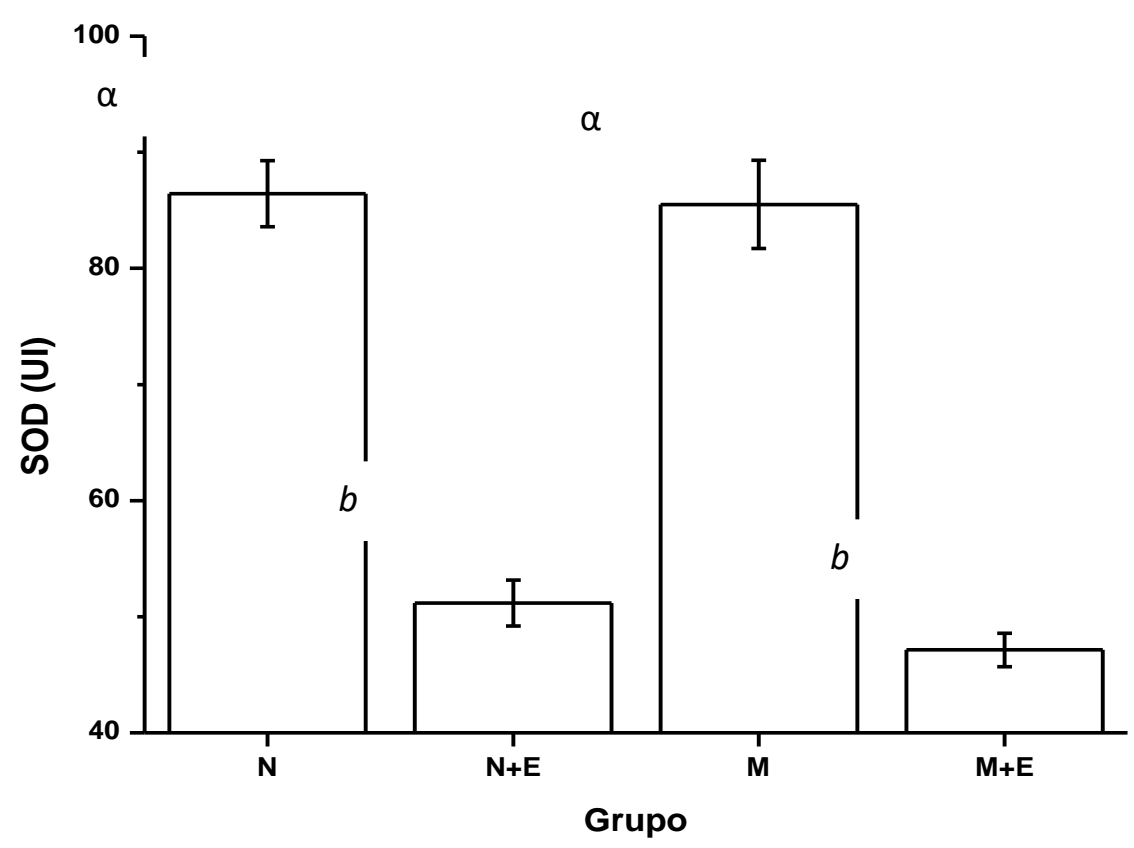

Legenda. $\mathrm{N}=$ Leite de vacas normais; $\mathrm{N}+\mathrm{E}=$ Leite de vacas normais com adição de extrato de Momordica charantia $; \mathrm{M}=$ Leite de vacas Mastíticas; $\mathrm{M}+\mathrm{E}=$ Leite de vacas mastíticas com a adição de extrato de Momordica charantia $L$.

Segundo Grover (2004) o extrato de M. Charantia L. é usado topicamente para o tratamento de feridas, e internamente, assim como externamente para a eliminação de parasitas é usado também como antiviral para o sarampo e a hepatite, externamente para cicatrização rápida das feridas e internamente para o tratamento de úlceras pépticas. Em estudos realizados por Manfrin (2009), que avaliou o efeito do extrato aquoso de M. Charantia sobre Eschechiria coli nas concentrações de 10,25 e $50 \mathrm{mg} / \mathrm{L}$, observou que o resultado foi bastante satisfatório no controle deste microrganismo em todas as concentrações. Brasileiro, et. al., (2006) avaliaram extratos de 32 espécies de plantas, dentre estas a M. Charantia, cujo extrato demonstrou atividade contra E. coli.

Foram encontrados na literatura consultada alguns estudos relacionados à atividade antimicrobiana de Momordica Charantia L. No entanto, quando o objetivo foi avaliar o potencial imunomodulador de plantas medicinais sobre os microrganismos causadores da mastite bovina percebe-se uma lacuna no conhecimento existente. Em contrapartida, Schuch et al (2008) produziram soluções desinfetantes a partir de folhas e talos de Baccharis trimera (nome comum Carqueja), Eucalyptus ssp. (Eucalipto) e Tagetes minuta (Cravo-de-defunto) para testar sua atividade antibacteriana sobre os microrganismos causadores da mastite bovina, S. aureus, Streptococcus agalactiae e Pseudomonas aeruginosa e concluíram que as plantas apresentaram potencial antimicrobiano. 
Silva et al. (2009) relataram que Staphylococcus aureus foram sensíveis à solução do extrato Mimosa tenuiflorada (Jurema preta) e ainda assinalaram que os extratos de plantas são utilizados há muitos anos por várias populações em todo o mundo no tratamento de várias doenças. Estudos realizados por Pereira et al. (2009a; 2009b, 2009c) demonstraram ação antimicrobiana in vitro de vários extratos de plantas testados sobre $S$. aureus e $S$. coagulase negativo isolados de vacas e búfalas com mastite.

Na Momordica charantia L. os principais metabolitos encontrados são: alcaloides, catequinas, esteroides e saponinas (FONTE??). De acordo com Rodrigues et al. (2010), plantas medicinais que apresentam saponinas na sua composição possuem normalmente uma capacidade anti-inflamatória, expectorante e larvicida.

Os resultados dos estudos que testaram a atividade antimicrobiana contra patógenos dos produtos fitoterápicos evidenciam que várias plantas possuem ação bactericida, mostrando a importância de se avaliar meios alternativos no tratamento de infecções causadas, principalmente contra microrganismos que apresentam multirresistência.

\section{Conclusão}

O extrato de Momordica charantia L. apresentou pouca toxidade às células, permitindo que estas continuassem viáveis mesmo em sua presença do extrato. Na dosagem de ânion superóxido notou-se uma redução nos grupos com extrato e com leite mastítico. Verificou-se que o extrato apresentou atividade antibacteriana capaz de diminuir as concentrações de SOD e aumentar a atividade microbicida dos fagócitos aumentando a capacidade de fagocitose das células do sistema imunológico. Desta forma, acredita-se que o extrato hidro etanólico de Momordica charantia L. pode ser considerado um potencial imunomodulador para mastite bovina.

\section{Referências}

Almeida, M. Z. (2011). Plantas Medicinais. (3a ed.), EDUFBA. 221p.

Assis, J. P., Sousa, R. P., Linhares. P. C. F., Pereira. M. F. S., \& Moreira. J. C. (2015). Avaliação biométrica de caracteres do melão de São Caetano (Momordica charantia L). Rev. bras. plantas med., 17(4), 505-514.

Bandeira, F. S. (2015). Bacterina de Staphylococcus aureus contendo própolis como adjuvante para controle da mastite. 2015. 112f. Tese (Doutorado em Ciências) - Programa de Pós-Graduação em Veterinária, Faculdade de Veterinária, Universidade Federal de Pelotas, Pelotas.

Baskin, C. R., Hinchcliff, K. W., Disilvestro, R. A., Reinhart, G. A., Hayer, M. G., Chew, B. P., Burr, J. R., \& Swenson, R. A. Effects of dietary antioxidante supplementation on oxidative damage and resistance to oxidative damage during prolonged exercise in sled dogs. American Journal of Veterinary research. 61 , (8), 886-91.

Brasil, Ministério de Agricultura e do Abastecimento. (2002). Instrução normativa $n^{o} 51$ de 18 de setembro de 2002 . Regulamentos técnicos de produção, identidade, qualidade coleta e transporte de leite. Diário Oficial da União, Brasília, D.F. Secção 1. p.23-57.

Brasil, Ministério da Agricultura, Pecuária e Abastecimento. (2011). Instrução Normativa no 62, de 29 de dezembro de 2011.

Brasil. (2012). Mastite Bovina: Considerações e impactos econômicos. Embrapa Tabuleiros Costeiros.

Brasileiro B. G., Pizziolo, V. R., Raslan D.S., Jamal, C. M., \& Silveira, D. (2006). Triagem das atividades antimicrobiana e citotóxica de algumas plantas medicinais brasileiras usadas na cidade de Governador Valadares. Revista Brasileira de Ciências Farmacêuticas, 42(2):195-202.

Coelho-Ferreira, M. (2009). Medicinal knowledge and plant utilization in an Amazonian coastal community of Maruda, Para State (Brazil), Journal of Ethnopharmacology, 126,.159-175.

Conab- Companhia Nacional de Abastecimento. (2016). Conjuntura Mensal, Leite e Derivados.

Corrêa, V. S. C., Maynié, J. C., França, E. L., \& Honório-França, A.C. (2006). Atividade funcional de fagócitos na presença do fitoterápico 'Mais Vida'. Rev. Bras. Pl. Med., Botucatu, 8(2), 26-32.

Costa, A. C. (2010). Mastite subclínica: patógenos isolados e respectiva sensibilidade antimicrobiana, variação da contagem de células somáticas e fatores de risco. 102 p. Dissertação (Programa de Pós-Graduação em Ciência Animal) - Universidade Federal de Goiás, Goiânia.

Costa, J. R., \& Mitja, D. (2010). Uso dos recursos vegetais por agricultores familiares de Manacapuru (AM). Acta Amaz, 40(1), 49-58. 
Costa, V.P., Mayworm, M.A.S. (2011). Plantas medicinais utilizadas pela comunidade do bairro dos Tenentes - município de Extrema, MG, Brasil. Revista Brasileira de Plantas Medicinais, 13(3), 282-92.

Cunha, A. F., Bragança. L. J., Quintão. L. C., Coelho. K. S., Souza. F. N., Cerqueira. M. M. O. P. (2016). Prevalência, etiologia e fatores de risco de mastite clínica em rebanhos leiteiros de viçosa-MG. Acta Veterinaria Brasilica, 10(1), 48-54.

Cunha, S.A., Bortolotto, I.M. (2011). Etnobotânica de Plantas Medicinais no Assentamento Monjolinho, município de Anastácio, Mato Grosso do Sul, Brasil. Acta Botânica Brasílica, 25(3), 685-98.

Das, S. S. Saha \& B. Bishayi. (2008). Intracellular survival of Staphylococcus aureus: correlating production of catalase and superoxide dismutase with levels of inflammatory cytokines. Inflamm. res. 57, 340-349.

Embrapa Gado De Leite. (2010). Principais países produtores de leite no mundo. http://www.cnpgl.embrapa.br/nova/infor macoes/estatisticas/producao/producao.php. Acesso em: 19/06/2017.

Embrapa - empresa brasileira de pesquisa agropecuária. Anuário do leite 2019. http://ainfo.cnptia.embrapa.br/digital/bitstrea m/item/198698/1/AnuarioLEITE2019.pdf.

Evangelista, S. S, Sampaio, F. C, Parente, R. C, Bandeira, M. F. C. L. (2013). Fitoterápicos na odontologia: estudo etnobotânico na cidade de Manaus. Rev. bras. plantas med., 15(4), 513-9.

França, E. L., Morceli, G., Fagundes, D. L.G., Calderon, I. M. P., Honório-França, A. C. (2011). Secretory IgA Fc $\alpha$ receptor interaction modulating phagocytosis and microbicidal activity by phagocytes in human colostrum of diabetics. APMIS 119: 710-719.

Freitas, R. C., Azevedo, R. R. S., Souza, L. I. O., Rocha, T. J. M., Santos, A. F., et al. (2014). Avaliação da atividade antimicrobiana e antioxidante das espécies Plectranthus amboinicus (Lour.) e Mentha x villosa (Huds.). Rev Ciênc Farm Básica Apl. 35(1):113-118.

Fuangchana A, Sonthisombata P, Seubnukarnb T, Chanouanc R, Chotchaisuwatd P, Sirigulsatien V, Ingkaninan K, Plianbangchang P, Haines, S.T. (2011). Hypoglycemic effect of bitter melon compared with metformin in newly diagnosed type 2 diabetes patients. J Ethnopharmacol. p.134:422-8.

Gill, J., G., Piskounova, E., Morrison, S., J. Cancer, Oxidative Stress, and Metastasis. Cold Spring Harbor Laboratory Press. 81, 1-13, 2016.

Gonçalves, J. N. (2012). Manual do Produtor de leite. 864 p.

Gonzatti, M. B. (2015). Atividade Funcional de fagócitos monoucleares na presença de Lippia sidoides e Streptococcus mutans. Monografia- Universidade Federal de Mato Grosso, Campus universitário do Araguaia. 41 p.

Grover J. K, Yadav S. P. (2004). Pharmacological actions and potential uses of Momordica charantia: a review. J Ethnopharmacol. 93:123-32.

Honorio, A. C. (1995). Atividade bactericida dos fagócitos do colostro humano para Escherichia coli enteropatogênica (EPEC). 115p. Dissertação (Mestrado) - Departamento de Imunologia, Instituto de Ciências Biomédicas, Universidade de São Paulo, São Paulo.

Honorio-França, A. C. et al. (2001). Colostral neutrophils express IgA Fc receptors (CD89) lacking y chain association that mediate non-inflammatory properties of secretory IgA. Journal of Leukocyte Biology, 69(2), 289-96.

Ibge, Indicadores IBGE, Estatística da Produção Pecuária. Dezembro de 2018. <http://www.ibge.gov.br/home/estatistica/indicadores/agropecuari a/producaoagropecuaria/abate-leite-couro-ovos_201103_publ_completa.pdf>.

Ibge, Indicadores IBGE, Estatística da Produção Pecuária. Dezembro de 2018 . <http://www.ibge.gov.br/home/estatistica/indicadores/ agropecuaria/producaoagropecuaria/abate-leite-couro-ovos_201103_publ_completa.pdf $>$.

Krewer, C. C. et al. (2013). Etiology, antimicrobial susceptibility profile of Staphylococcus spp. and risk factors associated with bovine mastitis in the states of Bahia and Pernambuco. Pesquisa Veterinária Brasileira, 33(5), 601-606, maio.

Lazzari, A. M. et al. (2014). Produção de interleucina-1 beta e severidade da mastite pós-inoculação de S. aureus na glândula mamária de bovinos e bubalinos. Ciência Rural, 44(10), 1816-1822.

Lenzi. M., Orth. A. I., Guerra. T. M. (2005). Ecologia da polinização de Momordica charantia L. (Cucurbitaceae), em Florianópolis, SC, Brasil. Revista Brasil. Bot., 28(3). 505-313.

Lopes, L.O, Lacerda, M.S, Ronda, J.B. (2013). Uso de antibióticos na cura e controle de mastite clínica e subclínica causada por principais microrganismos contagiosos em bovinos leiteiros: revisão de literatura. Revista Científica Eletrônica de Medicina Veterinária. (21), 1-15.

Lorenzi. H. (2008). Plantas daninhas do Brasil: terrestres, aquáticas, parasitas e toxicas. Instituto Plantarum, (4a ed.).

Manfrin, M. G., Vieira, J. A., Leme, S. G. F., Borges, C. M. (2009). Estudo da Atividade Antimicrobiana da Momordica charantia L. (Cucurbitaceae) em Sistemas de Injeção em Fluxo, 32a Reunião Anual da Sociedade Brasileira de Química, Fortaleza - CE.

Marinho, M. G. V. et al. (2011). Levantamento etnobotânico de plantas medicinais em área de caatinga no município de São José de Espinharas, Paraíba, Brasil. Revista Brasileira de Plantas Medicinais, 13(2), 170-82.

Marques, V. F., Miliane M. S., Souza, M. M. S., Mendonça, E. C. L., Alencar, T. A., Pribul, B. R., Coelho, S. M. O., Lasagno, M., Elina B. Reinoso, E. B. (2013). Análise fenotípica e genotípica da virulência de Staphylococcus spp. e de sua dispersão clonal como contribuição ao estudo da mastite bovina. Pesq. Vet. Bras, 33(2), 161-170.

Mazzari, A. L. D. A., Prieto, J. M. (2004). Herbal medicines in Brasil: Pharmacokinetic profile and potencial herb-drug interactions. Frontiers in Pharmacology, $5,1-12$ 
Mendes, A. R., Andreazzi, M. A., Simonelli, S. M., Cavalieri, F. L. B., \& Silva, V. E. G. Gestão da qualidade do leite promove ganhos econômicos e ambientais. Research, Society and Development, 10(2), e45910212250, 10.33448/rsd-v10i2.12250. https://rsdjournal.org/index.php/rsd/article/view/12250.

Millezi, A. F., Baptista, N. N., Caixeta, D. S., Rossoni, D. F., Cardoso, M. G., \& Piccoli R. H. (2014). Caracterização química e atividade antibacteriana de óleos essenciais de plantas condimentares e medicinais contra Staphylococcus aureus e Escherichia coli. Revista Brasileira de Plantas Medicinais, v.16, n.1, p.18-24.

Moghadam, M. M., Amiri, M., Riabi, H. R., Riabi, H. R. (2016). Evaluation of antibiotic residues in pasteurized and raw milk distributed in the South of Khorasan-e Razavi Province, Iran. Journal of Clinical and Diagnostic Research, 10(12), 31-35. https://10.7860/JCDR/2016/21034.9034

Moreira. R. C. T., Costa. L. C. B., Costa. R. C. S., Rocha. E. A. (2002). Abordagem Etnobotânica acerca do Uso de Plantas Medicinais na Vila Cachoeira, Ilhéus, Bahia, Brasil. Acta Farm. Bonaerense. Junho.

Neto J. R. A., Barros R. F. M., Silva P. R. R. (2015). Uso de plantas medicinais em comunidades rurais da Serra do Passa-Tempo, estado do Piauí, Nordeste do Brasil. R. Bras. Bioci, 13(3), 165-175.

Oecd-Fao Perspectivas agrícolas 2015. (2015). Oecd Publishing.

Oliveira, A.K.M. et al. (2011). Ethnobotany and traditional medicine of the inhabitants of the Pantanal Negro sub-region and the raizeiros of Miranda and Aquidauna, Mato Grosso do Sul, Brazil. Brazilian Journal of Biology, 71(1), 1.1:283-9.

Oliveira, A. C., Valentim, I. B., Goulart, M. O. F., Silva, C. A., Bechara, E. J. H., Trevisan, M. T. S. (2009). Fontes vegetais naturais de antioxidantes. Quin Nova. 32. 689-702.

Ormonde, J. V. S. (2012). Potencial imunomodulador do extrato de Melão de São Caetano (Momordica charantia) em fagócitos de sangue periférico humano. 43 p. Monografia (Graduação em Biomedicina) - Universidade Federal de Mato Grosso, Campus universitário do Araguaia. Barra do Garças.

Pereira, A. (2010). Avaliação das atividades antitumoral e cicatrizante de extratos provenientes da casca de banana cultivar Prata Anã (Musa spp.). Dissertação (Pós-Graduação em Biotecnologia) Universidade Federal de Santa Catarina - Florianópolis.

Pereira, A. V., Lôbo, K. M. S., Bezerra, D. A. C., Rodrigues, O. G., Athayde, A. C. R., Mota, R. A., De Lima, E. Q., \& De Medeiros, E. S. (2009a). Perfil de sensibilidade antimicrobiana in vitro de jurema preta e neem sobre amostras de Staphylococcus sp. isoladas de mastite em búfalas. Arquivos do Instituto Biológico. 76(3), 341-346.

Pereira, A. V., Rodrigues, O. G., Azevedo, T. K. B., Bezerra, D. A. C., De Lima, E. Q., \& Pereira, M. S. (2009b). Perfil de extrato de plantas sobre Staphylococcus aureus isolado de mastite bovina. Revista de Biologia e Farmácia. 3(1), 105-111.

Pereira, A. V., Rodrigues, O. G., De Lima, E. Q., Oliveira, K. A., Mota, R. A., \& De Medeiros, E. S. (2009c). Estudo comparativo da atividade antimicrobiana de extrato de Jurema preta (Mimosa tenuiflora) e antibióticos sintéticos utilizados no tratamento de mastite em bubalinos. Revista de Biologia e Farmácia. SSN 1983-4209, 3(1), 105-111.

Pinto, M. S. (2000). Efeito antimicrobiano de própolis verde do estado de Minas Gerais sobre bactérias isoladas do leite de vacas com mastite. 104p. Tese (Pós-Graduação em Medicina Veterinária) - Universidade Federal de Viçosa.

Pitchakarn P, Suzuki S, Ogawa K, Pompimon W, Takahashi S, Asamoto M, et al. (2012). A triterpeniod from Momordica charantia leaf, modulates the progression of androgen-independent human prostate cancer cell line, PC3. Food Chem Toxicol. 50:840-7.

Ponzi, E. A. C., Oliveira, T. L., Morais, I. A. F., Junior, J. J. S., Gerbi, M. M., Souza, I. A., Psiottano, M. N. C., Xavier, M. S. (2010). Atividade antimicrobiana do extrato de Momordica charantia L. Revista de cirurgia e traumatologia. 10.

Possenti, C. G. R., Horn, R. C., Mori, N. C., Ribas Junior, V., Golle, D. P., \& Koefender, J. (2018). Avaliação De Estresse Oxidativo No Plasma De Bovinos Leiteiros Com Mastite. Cienc. anim. bras., 19(1-9), e-39754.

Rakholiya K, Kaneria M, Chanda S. (2011). Vegetable and fruit peels as a novel source of antioxidants. J Med Plants Res. 5:63-71.

Rodrigues, K. A. F., Dias, C. N., Florencio, J. C., Vilanova, C. N., Gonçalves, J. R. S., \& Moraes, D. F. C. (2010). Prospecção Fotoquímica e Atividade Moluscicida de folhas de Momordica charantia L. Cadernos de Pesquisa, 17(2).

Rosa, C., Câmara, S.G., Béria, J.U. (2011). Representações e intenção de uso da fitoterapia na atenção básica à saúde. Ciências \& Saúde Coletiva, 16(1), 311318.

Santos, L. F. Coelho, K. S., Cunha, A. F., Nunes, M. F., \& Miranda, J. P. M. (2015). Influência de parâmetros físico-químicos do leite na detecção de mastite subclínica bovina por condutividade elétrica. Revista Científica Univiçosa. 7(1), 1-6.

Schuch, L. F. D., Wiest, J. M., Coimbra, H. S., Prestes, L. S., Toni, L., \& Lemos, J. S. (2008). Cinética da atividade antibacteriana in vitro de extratos naturais frente a microrganismos relacionados à mastite bovina. Ciência Animal Brasileira. 9(1), 161-169.

Seab - Secretaria de Estado da Agricultura e do Abastecimento. (2014). Departamento de Economia Rural. Análise da Conjuntura Agropecuária do leite.

Silva, A. M., Silva, J. C. S., Silva, M. L. K., Oliveira, A. R. N., \& Moura, D. M. F. (2017). Conjuntura da pecuária leiteira no Brasil. Revista Eletrônica. (1), 14.

Silva, V. A., Freitas, A. F. R., Pereira, M. S. V., \& Lacerda, J. T. J. G. (2009). Avaliação da atividade antimicrobiana in vitro da Mimosa tenuiflora (Willd) Poir. (Jurema Preta) sobre linhagens de Staphylococcus aureus de origem bovina. In: $25^{\circ}$ Congresso Brasileiro de Microbiologia. Anais eletrônicos.... [Online]. http://sbmicrobiologia.org.br/PDF/cdsbm/resumos/R0285-1.html 
Research, Society and Development, v. 10, n. 6, e36010614267, 2021

(CC BY 4.0) | ISSN 2525-3409 | DOI: http://dx.doi.org/10.33448/rsd-v10i6.14267

Souza, V. (2010). Epidemiologia molecular dos Staphylococcus aureus isolados em diferentes pontos do fluxograma de produção do leite. pag. 3-5, 8. Tese de Doutorado - Faculdade de Ciências Agrárias e Veterinárias, Jaboticabal - SP.

Spears, J. W., \& Weiss, W. P. Role of antioxidants and trace elements in health and immunity of transition dairy cows. The Veterinary Journal, 176(1), 70- 76, 2008 .

Teixeira, C. M. S., Araújo, M. L. M., Ferreira, C. T. P. A., \& Viana, M. G. S. (2017). Mastite bovina ocasionada por Staphylococcus aureus e suas implicações em saúde pública. Revista Brasileira de Agrotecnologia 7(1), 119-121.

Tozzetti, D. S., Bataier, M. N., Almeida, L. R., \& Piccinin, A. (2008). Prevenção, controle e tratamento das mastites bovinas - revisão de literatura. Revista científica eletrônica de medicina veterinária. VI(10), Periódicos Semestral.

Voges, J. G., Thaler Neto, A., \& Kazama, D. C. S. (2016). Qualidade do leite e a sua relação com o sistema de produção e a estrutura para ordenha. Revista Brasileira de Ciência Veterinária, 22(3-4), 171-175.

Yeo, Y. L., Chia, Y. Y Lee, C. H., Sow, H. S., \& Yap W. S. (2014). Effectiveness of Maceration Periods with Different Extraction Solvents on in-vitro Antimicrobial Activity from Fruit of Momordica charantia L. Journal of Applied Pharmaceutical Science. 4 (10), 016-023. 